\title{
The New Coronavirus COVID-19 Infection
}

\author{
M. R. Bevova ${ }^{a}$, S. V. Netesov ${ }^{b}$, and Yu. S. Aulchenko ${ }^{b, c, *}$ \\ ${ }^{a}$ University of Liège, Liège, 4000 Belgium \\ ${ }^{b}$ Novosibirsk State University, Novosibirsk, 630090 Russia \\ ${ }^{c}$ Federal Research Center Institute of Cytology and Genetics, Siberian Branch, \\ Russian Academy of Sciences, Novosibirsk, 630090 Russia \\ *e-mail:yurii@bionet.nsc.ru
}

Received April 3, 2020; revised April 16, 2020; accepted April 18, 2020

\begin{abstract}
In December 2019, the first cases of pneumonia of unknown etiology were found in Wuhan (China). Later, the pneumonia was associated with a new coronavirus; in February 2020, the World Health Organization (WHO) gave the name COVID-19 to the new disease, while the International Committee on Taxonomy of Viruses (ICTV) gave the name SARS-CoV-2 to the virus causing it. By March 11, 2020, when the virus had spread to 114 countries, the number of diagnosed patients had reached 118 thousand and the number of deaths was 4000 , the WHO declared the outbreak of the disease a pandemic. In this review, we summarize the relevant information about the origin and spread of SARS-CoV-2, its epidemiology and diagnostics, and the clinical course and treatment of COVID-19.
\end{abstract}

Keywords: coronavirus, COVID-19, SARS-CoV-2, epidemiology

DOI: $10.3103 / \mathrm{S} 0891416820020044$

\section{ORIGIN AND SPREAD OF COVID-19}

In December 2019, cases of pneumonia of unknown etiology appeared in China in Hubei province. Almost all the first cases of the disease were found in individuals working in the market or visiting the seafood market in Wuhan. In January 2020, a new coronavirus was detected in patients with pneumonia [1]. In February 2020, the World Health Organization (WHO) gave the name COVID-19 to the new disease, while the International Committee on Taxonomy of Viruses (ICTV) gave the name SARS-CoV-2 to the virus.

By February 15, 2020, the number of individuals who had been diagnosed with COVID-19 in China exceeded 50 thousand, while a few (less than 50, except for Singapore and the cruise ship Diamond Princess) cases of the disease were observed in other countries [2]. Despite the quarantine measures that were taken, the disease spread rapidly. On March 11, 2020, the WHO declared the outbreak of the disease to be a pandemic [3]; by this time, the virus had spread to 114 countries, with the number of diagnosed patients having reached 118 thousand and the number of deaths 4 thousand [4]. When this article was written (April 16, 2020), the pandemic spanned 213 countries; in the world, there are more than 2 million cases and more than 134 thousand deaths from COVID-19 [5]. In many countries, the number of cases and deaths are growing exponentially. The current statistics is available on the WHO website (https://www.who.int/ emergencies/diseases/novel-coronavirus-2019/situation-reports/), on a Russian site (https://www.coro- navirus-monitor.ru), and on a web aggregator supported by Johns Hopkins University, United States (https:// gisanddata.maps.arcgis.com/apps/opsdashboard/index. html\#/bda7594740fd40299423467b48e9ecf6).

By mid-April, after China, the largest number of cases occurred in the United States, Italy, Spain, Germany, France, and the United Kingdom. While the epidemic in China had been brought under control by this time, with less than 100 new patients per day being detected, the center of the pandemic had moved to the United States and Europe, where tens of thousands of new cases were diagnosed in total every day. In the Russian Federation, there had been more than 24 thousand cases and more than 200 deaths as of April 16,2020 [5].

The reproduction number (the number of secondary cases of infection caused by one infected individual, $\mathrm{R}_{0}$ ) is estimated for COVID-19 as 2.2 (95\% confidence interval from 1.4 to 3.9) [6]. For comparison, seasonal influenza usually has a reproduction number of about 1.3 [7].

COVID-19 is transmitted by airborne droplet, airborne dust, and contact ways. It has been demonstrated that infection can be transmitted, including from asymptomatic carriers and infected individuals, already in the incubation period of their disease or even within a few days after clinical recovery [8-10]. Outside the human organism, SARS-CoV-2 virus can maintain an ability to infect for up to 3 days on surfaces 
made of plastic and stainless steel, up to $24 \mathrm{~h}$ on cardboard, and up to $4 \mathrm{~h}$ on copper surfaces [11].

\section{SARS-CoV-2 VIRUS}

The virus genome was for the first time sequenced in China and uploaded to GenBank on January 10 , 2020 [12]. The first ten sequenced genomes were identical by $99.98 \%$, which indicates a single initial source of the epidemic. The sequence of SARS-CoV-2 was $96 \%$ identical to those for the bat CoV RaTG13 virus, 92\% identical to those for the Javan pangolin Pangolin- $\mathrm{CoV}$ virus [13], 79\% to those for the SARS-CoV virus, and $50 \%$ to those for the MERS-CoV virus. It is now believed that bats are a natural reservoir of the virus, but, apparently, there was an intermediate host, which is not currently identified; pangolins, cats, and dogs are under suspicion. Phylogenetic analysis of the genomes of virus isolates as compared with genomic sequences of more than 1000 natural strains and constructed laboratory strains confirms that SARS-CoV-2 virus has a natural origin [14-16].

SARS-CoV-2 virus belongs to the Riboviria realm, Nidovirales order, Cornidovirineae suborder, Coronaviridae family, Orthocoronavirinae subfamily, Betacoronavirus genus, Sarbecovirus subgenus, SARS-coronavirus species [17]. SARS-CoV and MERS-CoV viruses causing severe acute respiratory syndrome (SARS) and Middle East respiratory syndrome (MERS) belong to the same genus, subgenus, and species. Coronaviruses have a single-stranded plus RNA genome ranging in size from 26 to $32 \mathrm{~Kb}[15,16]$ and are divided into four genera: $\alpha, \beta, \gamma$, and $\delta$ [17]. Of them, $\alpha$ - and $\beta$-coronaviruses are mainly pathogens of mammals, while $\gamma$ - and $\delta$-viruses infect mammals and birds. SARS-CoV-2 belongs to the groups of $\beta$-coronaviruses. SARS-CoV-2 virus is the seventh known coronavirus that can cause disease in human beings. Of them, $\alpha-\mathrm{CoV}$ s HCoV-229E, HCoV-NL63, $\beta$-CoVs $\mathrm{HCoV}-\mathrm{HKU} 1$, and $\mathrm{HCoV}-\mathrm{OC} 43$ viruses usually have a low pathogenicity and mainly cause mild or moderate respiratory disease similar to influenza, although sometimes can cause severe pneumonia. SARS-CoV-1 and MERS-CoV viruses also belong to the genus of $\beta$-coronaviruses. SARS-CoV-1 virus caused the outbreak of atypical pneumonia in 2002-2003 [18], while MERS-CoV virus caused the outbreak of Middle East respiratory syndrome in 2012 and subsequent years [19].

To penetrate into human cells, SARS-CoV-2 uses the same receptor as SARS-CoV-1-namely, angiotensin-converting enzyme 2 (ACE2). The fusion of cell and virus membranes takes place with the involvement of cellular serine protease TMPRSS2 [20].

In vitro, SARS-CoV-2 viral particles can penetrate into the same cell cultures as SARS-CoV-1, for example, cultures of HEK-293T human cells, Vero E6 and Vero CCL81 green monkey cells, MDCKII dog cells, human adenocarcinoma cells (A549), and liver cells
(HUH7.0) [20]. In studies of viral replication and cytotoxicity, a number of cell lines were inoculated with the virus with a high multiplicity and was studied $24 \mathrm{~h}$ thereafter. No cytopathic effect was observed, except for in Vero cells, in which virus titers reached $>10^{7}$ PFU $24 \mathrm{~h}$ after infection. In contrast to this, HUH7.0 and HEK-293T cells demonstrated only a low level of replication, while A549 cells were not infected at all.

Upon observation, the plaques were more distinguishable and visible on Vero E6 culture. Two days after infection with a stronger dilution, VeroE6 cells produced separately distinguishable plaques clearly visible when stained with neutral red. In contrast to this, less transparent plaques were obtained on Vero CCL81 cells more distinguishable when stained with neutral red 3 days after infection [20].

For in vivo studies of SARS-Cov-2, such animals as rhesus macaques and transgenic (humanized) hACE2 laboratory mouse line were used. However, neither macaques nor mice develop a severe respiratory form of infection [21]. It was demonstrated that SARS-CoV-2 can replicate in the upper respiratory tract of ferrets, minks and domestic cats, while cats can infect other cats. At the same time, dogs, pigs, chickens, and ducks are little susceptible to infection [22].

\section{EPIDEMIOLOGY AND RISK FACTORS}

According to the results of studies of Chinese scientists, most patients $(87 \%)$ were $30-79$ years of age; $1 \%$, less than 9 years; $1 \%, 10-19$ years; and $3 \%$, over 80 years $[23,24]$. The estimation of the case-fatality rate (portion of deaths divided by the total number of cases) for the disease varies from 1 to $7 \%$ [24, 25] depending on the sex and age composition of the population; strategies of testing, diagnostics, and treatment; bureaucratic peculiarities of healthcare in a particular country; and congestion of healthcare systems. On March 3, 2020, the WHO estimated the mortality rate to be $3.4 \%$ [26]. However, the results of observations of the crew and passengers of the cruise ship Diamond Princess, on which 11 out of 712 patients died [5], lead to an estimation of the case-fatality rate of $1.5 \%$ (a 95\% confidence interval from 0.6 to $2.4 \%$ ).

Many studies have already demonstrated that the course of the disease and mortality are highly dependent on the patient's age and the presence of other diseases. In children, isolated cases of death have been registered. In the group up to 30 years, the mortality is about $0.2 \%$; after 40 years, the risk increases by three to four times with each additional decade, reaching approximately $8 \%$ in patients aged $70-79$ years and $15-20 \%$ after 80 years [23-25].

In addition to the elderly, individual with chronic diseases are in the high risk group. It has been demonstrated that arterial hypertension, heart diseases, diabe- 
tes, and obesity with a body mass index above 40 worsen the prognosis [24, 27].

At the same time, a severe course with a fatal outcome is also observed in individuals of middle age (30 years or older) without concomitant diseases. It is likely that these individuals have unknown risk factors-for example, an unfavorable genotype.

At present, there are insufficient data on the course of COVID-19 in pregnant women and on the effect of the disease on fetal and newborn development. Preliminary data from small samples have not shown the course of the disease to be more severe during pregnancy. The course of the disease was mild or moderate in most pregnant women [28] and newborns [29-32]. There are no data on the effect of COVID-19 on fetal development in the first and second trimesters of pregnancy.

\section{CLINICAL COURSE}

The incubation period of COVID-19 is from 2 to 14 days, with an average time of the onset of symptoms about 5 days [6]. Cases of the disease with an incubation period of more than 14 days have been described [23], but they are isolated and it is likely that they involved repeated and unrecorded contacts with virus carriers.

The clinical picture of the disease varies from asymptomatic cases to severe cases requiring hospital and resuscitation treatment. The typical clinical symptoms of COVID-19 include fever, dry cough, shortness of breath, myalgia, and fatigue. Other symptoms include headache, confusion, sternal pain, and diarrhea [33]. In more severe cases, bilateral pneumonia, acute respiratory distress syndrome (ARDS), multiple organ failure, and sepsis develop [34]. According to severity, the forms of the disease are classified into mild, moderate, and extremely severe [35].

Most clinical cases (81\%) of COVID-19 are classified as mild and moderate. In $14 \%$ of patients, the disease is severe with the presence of shortness of breath, a respiratory rate of $\geq 30 / \mathrm{min}$, blood oxygen saturation of $\leq 93 \%$, and a presence of infiltrates in the lungs of $>50 \%$ for $24-48 \mathrm{~h}$. About $5 \%$ of patients have the disease in an extremely severe form. The development of respiratory failure, septic shock, and failure of other organs are observed in them $[23,24]$.

After discharge, some patients are still virus carriers, this being confirmed by positive results of laboratory tests. Moreover, a relapse of the disease is observed in some patients [36]. Thus, at least in some patients, the immune response does not develop sufficiently to eliminate the virus. This may mean that vaccination can be inefficient for a certain group of individuals.

\section{DIAGNOSTICS}

On the basis of clinical symptoms, it is impossible to distinguish COVID-19 from other respiratory infections-in particular, from a cold or other acute respiratory viral infection. The collection of epidemiological data (travel history, patient contacts, etc.) is a key factor in differential diagnostics. The final diagnosis is made according to the results of laboratory tests, such as polymerase chain reaction (PCR), serological tests, and instrumental diagnostics (computed tomography).

\section{PCR DIAGNOSTICS}

The diagnostics is based on the amplification (reproduction) of specific viral genome regions by the reverse transcription PCR (RT-PCR) method [37, 38]. A nasopharyngeal and/or oropharyngeal swab is the main biomaterial for this study. At present, PCR diagnostics is used for many infectious diseases. Its advantages include the possibility of rapid development and production of the test as soon as the genomic sequence of the virus becomes known, as well as a very high sensitivity (up to just ten RNA molecules in the sample) and specificity of tests. The testing of SARS-CoV-2 is performed on the $N, S$ [39], ORF1ab, and E genes and their combinations. For example, the Chinese Center for Disease Control and Prevention recommends the use of primers to the ORFlab and $N$ genes. The test is considered positive if both genome regions are determined [40]. A number of Russian manufacturers registered their test systems at the end of March and already established production.

\section{SEROLOGICAL TESTS}

Using serological tests, it is possible to detect the presence of specific antibodies to the virus or the presence of an antigen in an organism. At the same time, combined testing using $\operatorname{IgM}$ and $\mathrm{IgG}$ antibodies to the virus is most frequently used. Testing for immunoglobulins $\mathrm{M}$ allows the fact of recent infection with a virus to be determined, while testing for immunoglobulins $G$ detects either a late stage of infection or immune response after recovery. An antibody test is very useful in the assessment of the immune status of the population and can allow an individual exit from the quarantine, as well as is required to estimate the immune status after vaccination. The minimum testing time is $15 \mathrm{~min}$, while final sensitivity and specificity during testing have been found to be 88.66 and $90.63 \%$, respectively [41].

An enzyme immunoassay test for a viral antigen, especially its express version, helps to identify a coronavirus etiology in the acute phase of infection. However, exact information about these tests or their sensitivity and specificity was unavailable at the time of writing this article. There are no data in the published literature yet concerning the possibility of differentiat- 
ing different human coronaviruses using serological tests.

\section{OTHER TESTS}

At present, tests based on the CRISPR method (for example, SHERLOCK and DETECTR) are being developed. Tests are based on the ability of the CRISPR system to recognize specific genome regions and cut them.

The specific high sensitivity enzymatic reporter unlocking (SHERLOCK) method is based on the use of Cas 13 for detecting viral RNA at a concentration from 10 to 100 RNA molecules per microliter. The results are visualized using an indicator test strip for $1 \mathrm{~h}$. The DETECTR method uses Cas12 to detect cDNA and is faster in execution (about $30 \mathrm{~min}$ ), but less sensitive, determining the presence of a viral genome in the sample with an initial concentration of 70-300 viral RNA molecules per microliter. At the time of writing this article, both tests were undergoing clinical trials [42].

Quick tests based on both simple PCR and isothermal PCR (including cartridge, for a field use) have also been developed. However, their sensitivity may be lower than in standard PCR tests. The analysis time for these tests is about $30 \mathrm{~min}$, which is acceptable for testing passengers at airports.

\section{TOMOGRAPHIC EXAMINATION}

A computed tomography is also used for the diagnosis of pneumonia caused by COVID-19 [43]. Bilateral infiltrates in the form of ground glass opacities or consolidation with the primary distribution in lower and middle zones of the lungs are detected with pneumonia caused by coronavirus [44].

\section{TREATMENT}

At the moment, there is no specific antiviral therapy for the treatment of COVID-19. Mild cases do not require special treatment. With the development of respiratory failure and pneumonia, the patient is hospitalized and a symptomatic therapy is provided. In severe cases, the treatment is aimed at maintaining the functions of vital organs. When attaching secondary bacterial infections, antibiotics can be prescribed [33]. Oxygen therapy is the main symptomatic treatment in severe cases. ARDS can develop against the background of a viral infection in severe patients. Such patients are transferred to mechanical ventilation (on a mechanical ventilator), and extracorporeal membrane oxygenation is used in more severe cases. With the severe form of the disease, the median time from the first symptoms to the development of shortness of breath is 5 days, to hospitalization 7 days, and to the development of ARDS 8 days [37].
At present, a large number of clinical trials for a number of drugs are being carried out. Testing drugs commonly used to treat other diseases is of special interest. These drugs were selected from among drugs with a potential antiviral activity or based on the hypotheses about the mechanism of virus action. In particular, the effect of such drugs as favipiravir (inhibitor of viral RNA polymerases produced in Japan), remdesivir (or GS-5743, nucleotide analogue, inhibitor of viral RNA polymerase developed by Gilead Sciences Co. (United States), but still at an earlier stage of clinical trials compared to other drugs) [45], combination of lopinavir and ritonavir (protease inhibitors used in the treatment of hepatitis C and HIV infection), and antimalarial drugs chloroquine and hydroxychloroquine (increase endosomal $\mathrm{pH}$ and violate terminal glycosylation of ACE2) are being widely investigated. Preliminary studies did not confirm the efficiency of treatment with lopinavir and ritonavir [46]. The efficiency of remdesivir and chloroquine was proven in experiments in vitro [47]. The efficiency of hydroxychloroquine was demonstrated in preliminary, yet very limited, clinical trials [48] that are currently criticized for unreliability. It should be noted that hydroxychloroquine can have severe side effects and interact with other drugs. At present, the WHO has initiated a global clinical study of these drugs, named Solidarity [49].

Scientists from different countries are engaged in the development of vaccines against the disease caused by SARS-CoV-2. There are several approaches to the development of antiviral vaccines. In particular, vaccines based on attenuated or inactivated virus, viral vectors, recombinant mRNA and DNA, and recombinant proteins are undergoing preclinical trials [50]. Phase I clinical trials started on volunteers in United States for a vaccine based on recombinant mRNA (Modetna Co.) and in China for a vaccine based on recombinant live adenovirus (fifth serotype) (CanSino Biologics Co.). In the event of success in the phase I trial, the phases II and III will be held in outbreaks in United States and China in summer. Full cycles of testing for the efficiency and safety of vaccines will take at least a year.

\section{DISCUSSION}

There are currently no answers to many questions about the COVID-19 disease and the SARS-CoV-2 virus itself. There are no accurate estimations of the portion of virus-infected individuals who are asymptomatic carriers or carry the disease in a mild form without getting into the official statistics. If this portion is high and such individuals transmit the disease, then, on the one hand, it will be very difficult to stop infection by currently taking quarantine measures, which, in many countries, are based on isolation of symptomatic cases and their contacts. 
On the other hand, this means that the estimations of the number of patients requiring hospital treatment and mortality rate are overstated. According to one such estimate, the portion of asymptomatic carriers may be as high as $60 \%$ of the total number of infected individuals [51], and at least some asymptomatic infected individuals can infect other individuals [10].

Although the existing estimations of the mortality rate and the amount of patients requiring hospitalization and intensive therapy may be overstated, it is clear that the number of COVID-19 patients who simultaneously need hospitalization and resuscitation measures is many times higher than the rates of habitual infections such as seasonal influenza. This is clear from the fact that the healthcare systems of the regions in Hubei and northern Italy, in which SARS-CoV-2 spread uncontrollably for some time, were close to collapse.

The number of patients simultaneously requiring medical assistance is affected by the virulence and the rate of infection in the population. An exact estimation of epidemiological parameters of COVID-19 is important for the development of mathematical models that are used by experts to predict the development of the situation. Defining a set of quarantine measures is one of the main tasks solved by these methods. Quarantine measures are aimed at suppressing or slowing down the spread of the virus, thus optimizing healthcare opportunities and minimizing the mortality and economic effect from the pandemic [52]. In particular, the number of patients requiring hospitalization is an important target parameter. Their number should not exceed the number of available hospital beds in the healthcare system.

A reliable identification of the dynamics of the number of infected individuals is extremely important for making government decisions and for understanding how efficient the measures taken are. At present, the WHO is calling for as many tests for SARS-CoV-2 as possible to control the spread of the disease [53], since, apparently, it is impossible to cope with the pandemic without it. Establishing the exact number of infected individuals is extremely difficult due to the difficulties of total and repeated screening of the population. The experience of the Netherlands and Denmark, where monitoring of the dynamics of the number of infected individuals is carried out by determining the content of viral RNA in the sewer, is interesting [54]. However, the efficiency and accuracy of this approach to fighting the epidemic is still unclear.

There is also no clear answer to the question of how stable immunity to COVID-19 is. News sites have disseminated information on several cases in which a patient repeatedly contracted COVID-19 [55]. It is unclear whether these are cases of reinfected individuals, a relapse of the disease, or a result of the first test result being a false positive. However, a recent study on rhesus monkeys showed that reinfection is unlikely
[56] (it should be noted that, by the moment of writing this review, this article had appeared in the form of a reprint and had not yet been reviewed).

The issue of the seasonality of COVID-19 remains unclear. There is an hypothesis that the reproductive number will decrease with the onset of summer in the Northern Hemisphere, which will lead to a slowing down of the spread of infection. There is also a hypothesis that, due to isolation of seriously ill patients, the most pathogenic variants of the virus will not be distributed and will be displaced by weakly pathogenic variants from asymptomatic carriers. The current virus will then become just another coronavirus causing ordinary acute respiratory viral infection. These hypotheses will be tested by nature and life itself in the next 3-4 months.

It is interesting to note that, although children are infected with the virus, they get sick in a milder form as compared with adults [57]; there are currently no data on death of children under the age of 10 years [25]. It is hypothesized that children may have a fresher immune response to antigenically similar infection, as well as a different level of ACE2 receptors on lung cells [58]. Experiments on model animals indeed demonstrated that specific number of ACE2 receptors plays an important role in the prevention of the development of acute respiratory failure [59], while the level of ACE2 decreases with age [60, 61]. However, no changes in the activity of ACE2 with age were observed in human beings in studies of ARDS [62]. The use of recombinant ACE2 was not efficient in the treatment of human ARDS [63].

In the future, it will be important to study the association of the symptoms and severity of the disease with different epidemiological and clinical risk factors, variations in genomic sequences of virus variants, and peculiarities of the genomes and immune systems of patients.

\section{ACKNOWLEDGMENTS}

The authors are grateful to G.A. Bazykin and S.A. Moshkovskii for discussion and to N.V. Aulchenko for assistance with the preparation of the article.

\section{FUNDING}

The work of Yu.S. Aulchenko was supported by the Ministry of Science and Higher Education of the Russian Federation through the Institute of Cytology and Genetics, Siberian Branch, Russian Academy of Sciences, budgetary project no. 0324-2019-0040-S-01/AAAA-A17-117092070032-4. The work of S.V. Netesov was supported by the Ministry of Science and Higher Education of the Russian Federation in the framework of the Basic Research Funding Grant \#FSUS2020-0035 of the Novosibirsk State University (NSU) and the Program for Improving the Competitiveness of Leading Universities of the Russian Federation among the World's Leading Research and Educational Centers, project no. 5-100. 


\section{COMPLIANCE WITH ETHICAL STANDARDS}

The authors declare that they have no conflict of interest. This article does not contain any studies involving animals or human participants performed by any of the authors.

\section{ADDITIONAL INFORMATION}

Bevova M.R.-e-mail: marianna.bevova@uliege.be; https://orcid.org/0000-0002-7788-6394

Netesov S.V.-e-mail: netesov.s@nsu.ru; https:// orcid.org/0000-0002-7786-2464

Aulchenko Yu.S._e-mail: yurii@bionet.nsc.ru; https:// orcid.org/0000-0002-7899-1575

\section{REFERENCES}

1. Zhu, N., Zhang, D., Wang, W., Li, X., Yang, B., Song, J., et al., A novel coronavirus from patients with pneumonia in China, 2019, N. Engl. J. Med., 2020, vol. 382, no. 8 , pp. 727-733.

2. Coronavirus Disease 2019 (COVID-19) Situation Report26, World Health Organization, February 15, 2020. https://www.who.int/docs/default-source/coronaviruse/ situation-reports/20200215-sitrep-26-covid-19.pdf? sfvrsn=a4cc6787 2. Accessed March 28, 2020.

3. Virtual Press Conference on COVID-19, March 11, 2020, World Health Organization, 2020. https://www.who. int/docs/default-source/coronaviruse/transcripts/whoaudio-emergencies-coronavirus-press-conference-fulland-final-11mar2020.pdf?sfvrsn $=$ cb432bb3_2. Accessed March 25, 2020.

4. Coronavirus Disease 2019 (COVID-19) Situation Report51, World Health Organization, March 11, 2020. https://www.who.int/docs/default-source/coronaviruse/ situation-reports/20200311-sitrep-51-covid-19.pdf? sfvrsn=1ba62e57 10. Accessed March 28, 2020.

5. Coronavirus Disease 2019 (COVID-19) Situation Report83, World Health Organization, April 12, 2020. https://www.who.int/docs/default-source/coronaviruse/ situation-reports/20200412-sitrep-83-covid-19.pdf? sfvrsn=697ce98d_4. Accessed April 13, 2020.

6. Li, Q., Guan, X., Wu, P., Wang, X., Zhou, L., Tong, Y., et al., Early transmission dynamics in Wuhan, China, of novel coronavirus-infected pneumonia, N. Engl. J. Med., 2020, vol. 382, pp. 1199-1207. https://doi.org/10.1056/NEJMoa2001316

7. Biggerstaff, M., Cauchemez, S., Reed, C., Gambhir, M., and Finelli, L., Estimates of the reproduction number for seasonal, pandemic, and zoonotic influenza: A systematic review of the literature, BMC Infect. Dis., 2014, vol. 14, no. 1, p. 407.

8. Li, P., Fu, J.-B., Li, K.-F., Chen, Y., Wang, H.-L., Liu, L.-J., et al., Transmission of COVID-19 in the terminal stage of incubation period: A familial cluster, Int. J. Infect. Dis., 2020, vol. 96, pp. 452-453. https://doi.org/10.1016/j.ijid.2020.03.027

9. Li, R., Pei, S., Chen, B., Song, Y., Zhang, T., Yang, W., et al., Substantial undocumented infection facilitates the rapid dissemination of novel coronavirus (SARSCoV2), Science, 2020, vol. 368, no. 6490, pp. 489-493. https://doi.org/10.1126/science.abb3221
10. Rothe, C., Schunk, M., Sothmann, P., Bretzel, G., Froeschl, G., Wallrauch, C., et al., Transmission of 2019-nCoV infection from an asymptomatic contact in Germany, N. Engl. J. Med., 2020, vol. 382, no. 10, pp. 970-971.

11. van Doremalen, N., Bushmaker, T., Morris, D.H., Holbrook, M.G., Gamble, A., Williamson, B.N., et al., Aerosol and surface stability of SARS-CoV-2 as compared with SARS-CoV-1, N. Engl. J. Med., 2020, vol. 382, pp. 1564-1567. https://doi.org/10.1056/NEJMc2004973

12. Lu, R., Zhao, X., Li, J., Niu, P., Yang, B., Wu, H., et al., Genomic characterization and epidemiology of 2019 novel coronavirus: Implications for virus origins and receptor binding, Lancet, 2020, vol. 395, no. 10224, pp. 565-574.

13. Zhang, T., Wu, Q., and Zhang, Z., Probable pangolin origin of SARS-CoV-2 associated with the COVID-19 outbreak, Curr. Biol., 2020, vol. 30, no. 7, pp. 13461351. https://doi.org/10.1016/j.cub.2020.03.022

14. Andersen, K.G., Rambaut, A., Lipkin, W.I., Holmes, E.C., and Garry, R.F., The proximal origin of SARS-CoV-2, Nat. Med., 2020, vol. 26, pp. 450-452. https://doi.org/10.1038/s41591-020-0820-9

15. Su, S., Wong, G., Shi, W., Liu, J., Lai, A.C.K., Zhou, J., et al., Epidemiology, genetic recombination, and pathogenesis of coronaviruses, Trends Microbiol., 2016, vol. 24, no. 6, pp. 490-502.

16. ICTV Taxonomy, International Committee on Taxonomy of Viruses (ICTV). https://talk.ictvonline.org/taxonomy/. Accessed March 29, 2020.

17. Perlman, S. and Netland, J., Coronaviruses postSARS: Update on replication and pathogenesis, Nat. Rev. Microbiol., 2009, vol. 7, no. 6, pp. 439-450.

18. Drosten, C., Günther, S., Preiser, W., van der Werf, S., Brodt, H.-R., Becker, S., et al., Identification of a novel coronavirus in patients with severe acute respiratory syndrome, N. Engl. J. Med., 2003, vol. 348, no. 20, pp. 1967-1976.

19. Zaki, A.M., van Boheemen, S., Bestebroer, T.M., Osterhaus, A.D.M.E., and Fouchier, R.A.M., Isolation of a novel coronavirus from a man with pneumonia in Saudi Arabia, N. Engl. J. Med., 2012, vol. 367, no. 19, pp. 1814-1820.

20. Hoffmann, M., Kleine-Weber, H., Schroeder, S., Krüger, N., Herrler, T., Erichsen, S., et al., SARSCoV-2 cell entry depends on ACE2 and TMPRSS2 and is blocked by a clinically proven protease inhibitor, Cell, 2020, vol. 181, no. 2, pp. 271-280. https://doi.org/10.1016/j.cell.2020.02.052

21. Callaway, E., Labs rush to study coronavirus in transgenic animals: Some are in short supply, Nature, 2020, vol. 579, no. 7798, p. 183.

22. Shi, J., Wen, Z., Zhong, G., Yang, H., Wang, C., Huang, B., et al., Susceptibility of ferrets, cats, dogs, and other domesticated animals to SARS-coronavirus 2 , Science, 2020, vol. 368, no. 6494, pp. 1016-1020. https://doi.org/10.1126/science.abb7015

23. Guan, W.-J., Ni, Z.-Y., Hu, Y., Liang, W.-H., Ou, C.-Q., He, J.-X., et al., Clinical characteristics of coronavirus disease 2019 in China, N. Engl. J. Med., 2020, vol. 382, 
pp. $1708-1720$.

https://doi.org/10.1056/NEJMoa2002032

24. Wu, Z. and McGoogan, J.M., Characteristics of and important lessons from the coronavirus disease 2019 (COVID-19) outbreak in China: Summary of a report of 72314 cases from the Chinese center for disease control and prevention, JAMA, J. Am. Med. Assoc., 2020, vol. 323, no. 13, pp. 1239-1242.

https://doi.org/10.1001/jama.2020.2648

25. Onder, G., Rezza, G., and Brusaferro, S., Case-fatality rate and characteristics of patients dying in relation to COVID-19 in Italy, JAMA, J. Am. Med. Assoc., 2020, vol. 323 , no. 18 , pp. 1775-1776. https://doi.org/10.1001/jama.2020.4683

26. WHO Director-General's Opening Remarks at the Media Briefing on COVID-19, March 3, 2020, World Health Organization, 2020. https://www.who.int/dg/speeches/ detail/whodirector-general-s-opening-remarks-at-themedia-briefing-on-covid-19-3-march-2020. Accessed March 25, 2020.

27. Zhou, F., Yu, T., Du, R., Fan, G., Liu, Y., Liu, Z., et al., Clinical course and risk factors for mortality of adult inpatients with COVID-19 in Wuhan, China: A retrospective cohort study, Lancet, 2020, vol. 395, no. 10229 , pp. 1054-1062.

https://doi.org/10.1016/s0140-6736(20)30566-3

28. Yu, N., Li, W., Kang, Q., Xiong, Z., Wang, S., Lin, X., et al., Clinical features and obstetric and neonatal outcomes of pregnant patients with COVID-19 in Wuhan, China: A retrospective, single-center, descriptive study, Lancet Infect. Dis., 2020, vol. 20, no. 5, pp. 559-564. https://doi.org/10.1016/S1473-3099(20)30176-6

29. Zeng, L., Xia, S., Yuan, W., Yan, K., Xiao, F., Shao, J., et al., Neonatal early-onset infection with SARS-CoV-2 in 33 neonates born to mothers with COVID-19 in Wuhan, China, JAMA Pediatr., 2020, vol. 174, no. 7, pp. $722-725$.

https://doi.org/10.1001/jamapediatrics.2020.0878

30. Zhu, H., Wang, L., Fang, C., Peng, S., Zhang, L., Chang, G., et al., Clinical analysis of 10 neonates born to mothers with 2019-nCoV pneumonia, Transl. Pediatr., 2020, vol. 9, no. 1, pp. 51-60.

31. Chen, H., Guo, J., Wang, C., Luo, F., Yu, X., Zhang, W., et al., Clinical characteristics and intrauterine vertical transmission potential of COVID-19 infection in nine pregnant women: a retrospective review of medical records, Lancet, 2020, vol. 395, no. 10226, pp. 809-815.

32. Wei, M., Yuan, J., Liu, Y., Fu, T., Yu, X., and Zhang, Z.-J., Novel coronavirus infection in hospitalized infants under 1 year of age in China, JAMA, J. Am. Med. Assoc., 2020, vol. 323, no. 13, pp. 1313-1314.

https://doi.org/10.1001/jama.2020.2131

33. Huang, C., Wang, Y., Li, X., Ren, L., Zhao, J., Hu, Y., et al., Clinical features of patients infected with 2019 novel coronavirus in Wuhan, China, Lancet, 2020, vol. 395 , no. 10223 , pp. 497-506.

34. Chen, N., Zhou, M., Dong, X., Qu, J., Gong, F., Han, Y., et al., Epidemiological and clinical characteristics of 99 cases of 2019 novel coronavirus pneumonia in $\mathrm{Wu}-$ han, China: A descriptive study, Lancet, 2020, vol. 395, no. 10223 , pp. 507-513.
35. Wang, Y., Wang, Y., Chen, Y., and Qin, Q., Unique epidemiological and clinical features of the emerging 2019 novel coronavirus pneumonia (COVID-19) implicate special control measures, J. Med. Virol., 2020, vol. 92, no. 6 , pp. $568-576$.

https://doi.org/10.1002/jmv.25748

36. Shi, Y., Wang, Y., Shao, C., Huang, J., Gan, J., Huang, X., et al., COVID-19 infection: The perspectives on immune responses, Cell Death Differ., 2020, vol. 27, no. 5, pp. $1451-1454$. https://doi.org/10.1038/s41418-020-0530-3

37. Wang, D., Hu, B., Hu, C., Zhu, F., Liu, X., Zhang, J., et al., Clinical characteristics of 138 hospitalized patients with 2019 novel coronavirus-infected pneumonia in Wuhan, China, JAMA, J. Am. Med. Assoc., 2020, vol. 323 , no. 11 , p. 1061.

38. Corman, V.M., Landt, O., Kaiser, M., Molenkamp, R., Meijer, A., Chu, D.K.W., et al., Detection of 2019 novel coronavirus (2019-nCoV) by real-time RT-PCR, Eurosurveillance, 2020, vol. 25, no. 3, p. 2431.

39. Zhou, P., Yang, X.-L., Wang, X.-G., Hu, B., Zhang, L., Zhang, W., et al., A pneumonia outbreak associated with a new coronavirus of probable bat origin, Nature, 2020, vol. 579, no. 7798, pp. 270-273.

40. Specific Primers and Probes for Detection 2019 Novel Coronavirus, Chinese National Institute for Viral Disease Control and Prevention, January 21, 2020. http:// ivdc.chinacdc.cn/kyjz/202001/t20200121_211337.html. Accessed March 25, 2020.

41. Sheridan, C., Fast, portable tests come online to curb coronavirus pandemic, Nat. Biotechnol., 2020, vol. 38, no. 5, pp. 515-518. https://doi.org/10.1038/d41587-020-00010-2

42. Subbaraman, N., Coronavirus tests: Researchers chase new diagnostics to fight the pandemic, Nature, 2020. https://doi.org/10.1038/d41586-020-00827-6

43. Pan, Y., Guan, H., Zhou, S., Wang, Y., Li, Q., Zhu, T., et al., Initial CT findings and temporal changes in patients with the novel coronavirus pneumonia (2019-nCoV): A study of 63 patients in Wuhan, China, Eur. Radiol., 2020, vol. 30, pp. 3306-3309.

https://doi.org/10.1007/s00330-020-06731-X

44. Li, M., Lei, P., Zeng, B., Li, Z., Yu, P., Fan, B., et al., Coronavirus disease (COVID-19): Spectrum of CT findings and temporal progression of the disease, Acad. Radiol., 2020, vol. 27, no. 5, pp. 603-608. https://doi.org/10.1016/j.acra.2020.03.003

45. Holshue, M.L., De Bolt, C., Lindquist, S., Lofy, K.H., Wiesman, J., Bruce, H., et al., First case of 2019 novel coronavirus in the United States, N. Engl. J. Med., 2020, vol. 382, no. 10, pp. 929-936.

46. Cao, B., Wang, Y., Wen, D., Liu, W., Wang, J., Fan, G., et al., A trial of lopinavir-ritonavir in adults hospitalized with severe Covid-19, N. Engl. J. Med., 2020, vol. 382, pp. 1787-1799. https://doi.org/10.1056/NEJMoa2001282

47. Wang, M., Cao, R., Zhang, L., Yang, X., Liu, J., Xu, M., et al., Remdesivir and chloroquine effectively inhibit the recently emerged novel coronavirus $(2019-\mathrm{nCoV})$ in vitro, Cell Res., 2020, vol. 30, no. 3, pp. 269-271.

48. Gautret, P., Lagier, J.-C., Parola, P., Hoang, V.T., Meddeb, L., Mailhe, M., et al., Hydroxychloroquine 
and azithromycin as a treatment of COVID-19: Results of an open-label non-randomized clinical trial, Int. J. Antimicrob. Agents, 2020, article 105949. https://doi.org/10.1016/j.ijantimicag.2020.105949

49. Kupferschmidt, K., WHO launches global megatrial of the four most promising coronavirus treatments, Science, 2020. https://doi.org/10.1126/science.abb8497

50. Graham, R.L., Donaldson, E.F., and Baric, R.S., A decade after SARS: Strategies for controlling emerging coronaviruses, Nat. Rev. Microbiol., 2013, vol. 11, no. 12 , pp. 836-848.

51. Qiu, J., Covert coronavirus infections could be seeding new outbreaks, Nature, 2020. https://doi.org/10.1038/d41586-020-00822-x

52. Enserink, M., Mathematics of life and death: How disease models shape national shutdowns and other pandemic policies, Science, 2020. https://doi.org/10.1126/science.abb8814

53. WHO Director-General's Opening Remarks at the Media Briefing on COVID-19, March 16, 2020, World Health Organization, 2020. https://www.who.int/dg/speeches/ detail/who-director-general-s-openingremarks-at-themedia-briefing-on-covid-19---16-march-2020. Accessed March 25, 2020.

54. What We Learn about the Corona Virus Through Waste Water Research, KWR, March 24, 2020. https://www. kwrwater.nl/en/actueel/what-can-we-learn-about-thecorona-virus-through-waste-water-research/. Accessed March 28, 2020.

55. Lawton, G., Can you catch the coronavirus twice? We don't know yet, New Sci., 2020. https://www.newscientist.com/article/mg24532754-600-can-you-catch-thecoronavirus-twice-we-dont-know-yet/. Accessed March 25, 2020.

56. Bao, L., Deng, W., Gao, H., Xiao, C., Liu, J., Xue, J., et al., Reinfection could not occur in SARS-CoV-2 in- fected rhesus macaques, bioRxiv, 2020. https://doi.org/10.1101/2020.03.13.990226

57. Zheng, F., Liao., C., Fan, Q.-H., Chen., H.-B., Zhao, X.-G., Xie, Z.-G., et al., Clinical characteristics of children with coronavirus disease 2019 in Hubei, China, Curr. Med. Sci., 2020, vol. 40, pp. 275-280. https://doi.org/10.1007/s11596-020-2172-6

58. King, A., Possible biological explanations for kids' escape from COVID-19, Sci. Mag., 2020. https://www. the-scientist.com/news-opinion/possible-biologicalexplanations-for-kids-escape-from-covid-19-67273. Accessed March 29, 2020.

59. Imai, Y., Kuba, K., Rao, S., Huan, Y., Guo, F., Guan, B., et al., Angiotensin-converting enzyme 2 protects from severe acute lung failure, Nature, 2005, vol. 436, no. 7047, pp. 112-116.

60. Schouten, L.R.A., Helmerhorst, H.J.F., Wagenaar, G.T.M., Haltenhof, T., Lutter, R., Roelofs, J.J.T.H., et al., Agedependent changes in the pulmonary renin-angiotensin system are associated with severity of lung injury in a model of acute lung injury in rats, Crit. Care Med., 2016, vol. 44, no. 12, pp. 1226-1235.

61. Xie, X., Chen, J., Wang, X., Zhang, F., and Liu, Y., Age- and gender-related difference of ACE2 expression in rat lung, Life Sci., 2006, vol. 78, no. 19, pp. 21662171.

62. Schouten, L.R., van Kaam, A.H., Kohse, F., Veltkamp, F., Bos, L.D., de Beer, F.M., et al., Age-dependent differences in pulmonary host responses in ARDS: a prospective observational cohort study, Ann. Intensive Care, 2019, vol. 9, no. 1, p. 55.

63. Khan, A., Benthin, C., Zeno, B., Albertson, T.E., Boyd, J., Christie, J.D., et al., A pilot clinical trial of recombinant human angiotensin-converting enzyme 2 in acute respiratory distress syndrome, Crit. Care, 2017, vol. 21 , no. 1 , p. 234.

Translated by A. Barkhash 